\title{
Carcinoma bronquíolo-alveolar difuso em um cão: aspectos clínico-patológicos e imuno- histoquímicos
}

\author{
Diffuse bronchioloalveolar carcinoma in a dog: clinicopathological and immunohistochemical findings
}

\author{
Ricardo Barbosa Lucena ${ }^{I^{*}}$ Lisanka Ângelo Maia'II Antônio Flávio Medeiros Dantas ${ }^{I I}$ \\ Verônica Medeiros da Trindade Nobre ${ }^{I I}$ Juliana Targino Silva Almeida Macêdo \\ Elias Marques Galiza Filho ${ }^{\text {III }}$ Claudio Severo Lombardo Barros
}

\section{- NOTA -}

\section{RESUMO}

Um cão Poodle, 12 anos de idade, demonstrou marcada dispneia. Na radiografia, havia comprometimento difuso do pulmão e foi feito diagnóstico de pneumonia intersticial. Na necropsia, o pulmão continha múltiplos e pequenos nódulos coalescentes. Histologicamente, os nódulos eram compostos por células epiteliais cuboides ou colunares baixas atípicas, que eram PAS-negativa. A avaliação imunohistoquímica revelou positividade para citoceratina, fator 1 de transcrição da tireoide (TTF-1) e apoproteina A surfactante $(S P-A)$. O tumor foi negativo para vimentina e cromogranina A. As áreas necróticas não marcaram para TTF-1 e SP-A. Com base nos achados histopatológicos e imuno-histoquímicos, foi realizado o diagnóstico de carcinoma bronquiolo-alveolar não mucinoso com envolvimento difuso do pulmão. Essa é uma forma rara de apresentação desse tumor que pode mimetizar pneumonia na avaliação clínica e radiográfica. $O$ diagnóstico definitivo é baseado na histopatologia e imunohistoquímica.

Palavras-chave: imuno-histoquimica, neoplasma, pulmão, câncer, patologia.

\section{ABSTRACT}

A 12-year-old poodle dog was presented with a history of severe dyspnea. Radiology revealed diffuse pulmonary lesion which was diagnosed as interstitial pneumonia. At necropsy there were multiple small coalescent nodules distributed throughout the lung parenchyma. Histologically the nodules consisted of cubic to low columnar atypical epithelial cells which were PAS-negatives. In the immunohistochemistry reaction this cells were marked for cytokeratin, TTF (thyroid transcription factor)- 1 and surfactant apoprotein A (SP-A). The neoplastic cells were negative for vimentin and cromagranine A. The necrotic areas were not marked for TTF1 and SP-A. Based of the histopathological and immunohistochemistry findings a diagnosis of non-mucinous bronchioloalveolar carcinoma with diffuse involvement of the lung was made. This is a rare form of presentation for this tumor, and it can mimetize pneumonia on clinical and morphological examination. A definitive diagnosis for this condition should be based on histopathology and immunohistochemistry.

Key words: immunohistochemistry, neoplasm, lung, cancer, pathology.

Neoplasmas pulmonares primários são incomuns em cães, com uma prevalência de 0,1-0,9\% (WILSON \& DUNGWORTH, 2002). São divididos em tumores de origem epitelial ou mesenquimal e classificados de acordo com o local de origem (broncogênico, glândula bronquial, ou bronquíoloalveolar), com o padrão histológico (adenoide, escamoso, grandes células, pequenas células), ou uma combinação destes (WILSON \& DUNGWORTH, 2002). Os carcinomas bronquíolo-alveolares (CBA) caracterizam-se pela proliferação de células neoplásicas

'Laboratório de Patologia Veterinária, Departamento de Patologia, Universidade Federal de Santa Maria (UFSM), Av. Roraima, 1000, Camobi, 97105-900, Santa Maria, RS, Brasil. E-mail: lucena.rb@gmail.com. *Autor para correspondência

"Hospital Veterinário, Centro de Saúde e Tecnologia Rural, (CSTR), Universidade Federal de Campina Grande (UFCG), Patos, PB, Brasil.

IIIMédico Veterinário autônomo, João Pessoa, PB, Brasil. 
ao longo dos alvéolos pulmonares e junções bronquíolo-alveolares pré-existentes, geralmente ocorrem como nódulos isolados ou na forma de múltiplas massas na periferia do pulmão (WILSON \& DUNGWORTH, 2002). A forma difusa do CBA é rara tanto em humanos quanto em animais, pode envolver grande parte ou todo o parênquima pulmonar induzindo ao diagnóstico de pneumonia na avaliação clínica e radiográfica (LUDINGTON et al., 1972; BERTAZZOLO et al., 2002). Histologicamente, neoplasmas primários de pulmão podem ser confundidos com metástases pulmonares de outras formas de câncer. Nesses casos, a avaliação imuno-histoquímica é imprescindível para confirmar a origem pulmonar do tumor (RAMOS-VARA et al., 2005). No presente relato, são descritos os aspectos clínicos, radiográficos, patológicos e avaliação imuno-histoquímica em diferentes secções de um caso de carcinoma bronquíolo-alveolar com envolvimento difuso do pulmão em um cão.

Um cão da raça Poodle, macho, de 12 anos de idade apresentou-se à consulta com histórico de emagrecimento progressivo, dificuldade respiratória e regurgitação após alimentação. Ao exame clínico, estava dispneico e taquipneico. Na radiografia do tórax, observaram-se extensas áreas de consolidação pulmonar e aumento da silhueta cardíaca. Foi feito um diagnóstico presuntivo de pneumonia. Institui-se antibioticoterapia. O cão não respondeu ao tratamento, houve agravamento do quadro seguido de morte.

$\mathrm{Na}$ necropsia observou-se um hidrotórax sanguinolento com cerca de $70 \mathrm{~mL}$. Os pulmões estavam aumentados de volume, firmes, com múltiplos nódulos salientes e irregulares, com diâmetro de $0,2-1,0 \mathrm{~cm}$ distribuídos por todo o parênquima (Figura 1A). Ao corte, verificou-se serem os nódulos constituídos por tecidos branco-amarelados e firmes, dando um aspecto de hepatização pulmonar (Figura 1B). Observou-se também dilatação cardíaca bilateral e fígado com aspecto de noz-moscada. Os demais órgãos não apresentaram alterações macroscópicas dignas de registro.

Fragmentos de pulmão, coração, rins, fígado, encéfalo, estômago, intestinos, baço, linfonodos, pâncreas e adrenais foram fixados em formol tamponado a $10 \%$, embebidos em parafina, seccionados a $3 \mu \mathrm{m}$ e corados com hematoxilina e eosina (HE) e feita avaliação histoquímica com ácido periódico de Schiff(PAS).

Histologicamente, nos pulmões, verificouse proliferação nodular multifocal a coalescente de células neoplásicas que revestiam estruturas alveolares ou papilas, com moderado estroma fibrovascular, lembrando a estrutura pulmonar pré-existente (Figura 1C). As células neoplásicas eram predominantemente cuboides a colunares baixas, com moderado pleomorfismo. Em alguns lobos, existiam extensas áreas de necrose intratumorais. Foram observados êmbolos de células neoplásicas no interior de vasos pulmonares sanguineos e linfáticos. Na coloração de PAS, não foi observada marcação positiva nas células tumorais. No fígado, havia moderada congestão da região centrolobular (congestão passiva crônica). Nos demais órgãos, não foram observadas alterações microscópicas.

A avaliação imuno-histoquímica foi realizada pela técnica da estreptavidina-biotina-peroxidase ${ }^{a}$ (EBP) em múltiplas secções do pulmão. A imunomarcação foi visualizada com o uso de 33'diaminabenzidina ${ }^{b}$ (DAB). As secções foram contracoradas com hematoxilina de Harris; utilizaramse controles positivos e negativos para cada anticorpo. Inicialmente, utilizou-se anticorpo anti-citoceratina ${ }^{c}$ (clone AE1/AE3, diluição 1:500) e anti-vimentinac (clone V9, diluição 1:100). As células neoplásicas demonstraram imunomarcação para citoceratina (Figura 1D), mas não para a vimentina. As secções também foram avaliadas para fator 1 de transcrição da tireoide ${ }^{c}$ (TTF-1) (clone 8G7G3/1, diluição 1:50) e para apoproteína A surfactante ${ }^{\mathrm{c}}$ (SP-A) (clone PE10, diluição 1:800). A reação para o TTF-1 foi nuclear e observada focalmente, principalmente nas margens das massas tumorais (Figura 1E). Nas secções avaliadas para SP$\mathrm{A}$, a reação foi observada em todas as áreas do tumor, exceto nas áreas necróticas, marcando o citoplasma e membrana citoplasmática das células neoplásicas (Figura 1F). Foi testado ainda o anticorpo anticromogranina $\mathrm{A}^{\mathrm{d}}$ (clone DAK-A3, diluição 1:600), que resultou em negatividade.

No presente relato, a aparência radiográfica do tumor mimetizou pneumonia, induzindo a este diagnóstico inicial. Em humanos e animais, tumores pulmonares difusos são comumente confundidos com pneumonia difusa (LUDINGTON et al., 1972; BERTAZZOLO et al., 2002). O diagnóstico definitivo nesses casos deve ser feito pelo exame histológico de material obtido por método de biópsia ou necropsia.

A classificação dos tumores de pulmão em humanos e animais é baseada no local de origem, no padrão histológico e/ou combinações destes (WILSON \& DUNGWORTH, 2002). Neste caso, a avaliação histológica foi compatível com carcinoma bronquíoloalveolar. A técnica histoquímica do PAS foi negativa para muco nas células tumorais, caracterizando um tumor do tipo não mucinoso. O pulmão é um dos principais sítios de metástases de neoplasmas não pulmonares, tornando-se muitas vezes complicado distinguir tumores pulmonares primários de metástases 


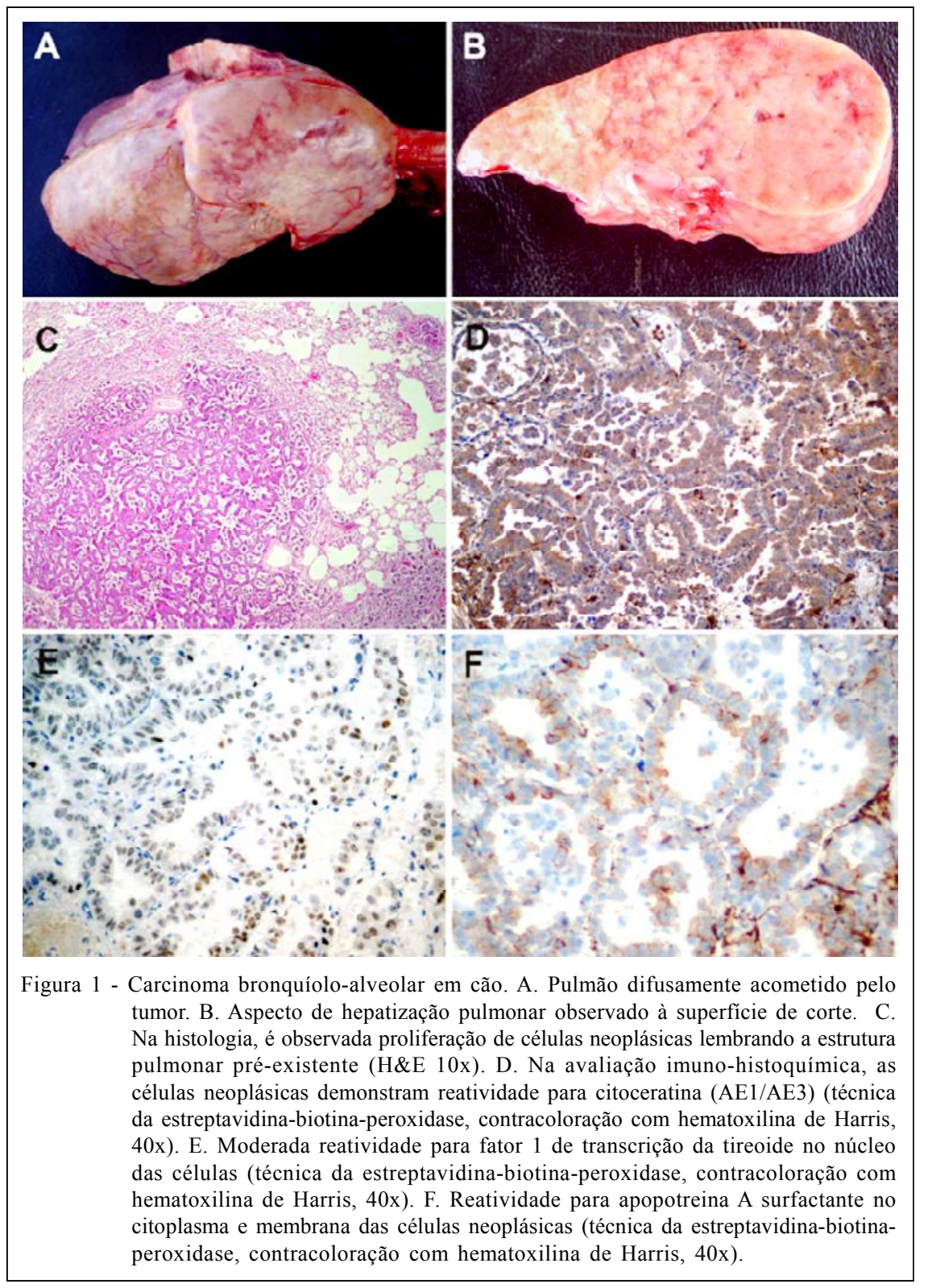

(RAMOS-VARA et al., 2005). Estudos imunohistoquímicos em tumores primários de pulmão são imprescindíveis para estabelecer o diagnóstico. No presente caso, a avaliação inicial demonstrou imunomarcação positiva para citoceratina e negativa para vimentina nas células tumorais, confirmando a origem epitelial do tumor.

Para comprovar a origem primária pulmonar, foi estabelecida análise para TTF-1 e SP-A. O TTF-1 tem sido apontado como um marcador altamente específico em adenocarcinomas pulmonares em humanos e cães (LAU et al., 2002, RAMOS-VARA et al., 2005). No entanto, não há relatos da avaliação desse marcador em múltiplas secções de tumores difusos do pulmão em cão. No cão deste relato, a marcação para TTF-1 foi observada preferencialmente na periferia das massas tumorais. Nas áreas de acentuada necrose e inflamação, a marcação foi fraca ou até ausente. Essa observação poderá tornar-se importante quando na análise do TTF-1 de fragmentos pequenos, obtidos por biópsia em áreas com acentuada necrose em CBA. É relatado ainda ausência de expressão para com esse anticorpo em CBA do tipo mucinoso ou áreas mucinosas (LAU et al., 2002, LUCENA et al., 2010). A imunomarcação SP-A demonstrou melhor distribuição quando comparada ao TTF-1. A reação negativa nas secções testadas com cromogranina A exclui a possibilidade de tratar-se de tumor neuroendócrino. 
O CBA difuso é um importante diagnóstico diferencial de pneumonia intersticial na avaliação clínica e radiográfica não só em pacientes humanos, mas também em cão. O exame histopatológico é indispensável para o diagnóstico de neoplasma pulmonar. A avaliação imuno-histoquímica é necessária para a comprovação da origem pulmonar do tumor. TTF1 e SP-A são anticorpos de escolha para a confirmação da origem do tumor.

\section{FONTES DE AQUISIÇÃO}

a-Complexo estreptavidina-biotina-peroxidase, Dako, Carpinteria, Califórnia, Estados Unidos da América (EUA). b-3,3-Diaminobenzidina, Sigma Chemical Co., St. Louis, Missouri, EUA.

c-Anti-pancitoceratina, anti-vimentina, anti-fator 1 de transcrição da tireoide, anti-apoproteína surfactante A, Dako, Carpinteria, Califórnia, EUA.

d-Anti-cronogranina A, Dako, Glostrup, Dinamarca.

\section{REFERÊNCIAS}

BERTAZZOLO, D.Z. et al. Diffuse bronchiolo-alveolar carcinoma in a dog. Journal of Small Animal Pratice, v.43, n.6, p.265-268, 2002. Disponível em: <http:// www3.interscience.wiley.com/cgi-bin/fulltext/118944040/ PDFSTART $>$. Acesso em: 10 ago. 2009. doi: 10.1111/j.17485827.2002.tb00065.x.

LAU, S.K. et al. Thyroid transcription factor-1: a review. Applied Immunohistochemistry \& Molecular Morphology, v.10, n.2, 97-102, 2002.

LUCENA, R.B. et al. Carcinoma bronquíolo-alveolar em leãoafricano (Panthera leo). Pesquisa Veterinária Brasileira, v.30, n.6, p.479-483, 2010. Disponível em: <http:// www.pvb.com.br/pdf_artigos/02-07-2010_1906Vet\%20800_1793\%20WM.pdf.> Acesso em: 07 jul. 2010.

RAMOS-VARA, J.A. et al. Usefulness of thyroid transcription factor-1 immunohistochemical staining in the differential diagnosis of primary pulmonary tumors of dogs. Veterinary Pathology, v.42, n.3, p.315-320, 2005. Disponível em: <http:/ /vet.sagepub.com/content/42/3/315.full.pdf + html $>$. Acesso em: 07 jul. 2010.

WILSON, D.W.; DUNGWORTH, D.L. Tumors of the respiratory tract. In: MEUTEN, D.J. Tumors in domestic animals. 4.ed. Ames: Iowa State University, 2002. p.365399. 